\title{
Fare Well to Tooth: A Hospital Based Study to Determine the Main Cause for Tooth Extraction
}

\author{
Rahul R. Bhowate ${ }^{1 *}$ and Mrunal G. Meshram² \\ ${ }^{1}$ Department of Oral Medicine and Radiology, Sharad pawar dental college and hospital, sawangi, Maharashtra. India \\ ${ }^{2}$ Department of Oral Medicine and Radiology, Sharad pawar dental college and hospital sawangi, Maharashtra. India
}

*Corresponding author: Dr. Rahul R. Bhowate Department of Oral Medicine and Radiology, Sharad pawar dental college and hospital, sawangi, Maharashtra. India

\begin{abstract}
Dental Surgeons play an important role in prevention of periodontal disease and caries. Good oral health is supposed to be the indicator of general health. Tooth mortality is directly related to the prevalence of periodontal disease and dental caries. In India, prevalence of periodontal disease is high and the only main cause of extractions [1-4]. But other studies carried out in various parts of India clearly showed a high incidence of caries involving almost the entire population [5-8]. The purpose of this present study was to determine the apparent reason for tooth extraction in hospital based study.
\end{abstract}

Keywords: Extraction; Dental caries; Periodontal disease; Trauma

\section{Materials and Methods}

Prospective study has been carried out for the cause of tooth extraction, in Sharad Pawar Dental College and Hospital, Sawangi (Meghe), Wardha, Maharashtra from $25^{\text {th }}$ June 09 to $30^{\text {th }}$ December 09.

The cause for tooth extraction was determined in the following way.

a) Caries: Whenever the primary reason is caries and/or its associated complication, e.g. failed endodontic treatment, secondary caries involving periapical tissues.

b) Periodontal Disease: Where severe gingival recession, loose tooth, periodontal abscess, or when periodontically involved tooth is extracted for prosthetic rehabilitation.

c) Where tooth is fully or partially impacted, traumatized noncarious tooth, over retained deciduous tooth, supernumerary teeth.

d) The data was analysed in respect of age, sex and type of tooth extracted.

\section{Results}

A total of 1332 individuals were analysed for the cause of tooth extractions. There was significantly highest percentage of extractions in male patients (61.78\%) compared to female patients (38.21\%) (Table 1). The age group 55 and above presented highest number of patients for extracted teeth $(31.15 \%)$ (Table 1$)$. The periodontal disease was the most common reason for tooth extractions (52.17\%). Dental caries was the second most cause for tooth extractions (43.16\%) (Table 2). When the entire sample was considered, under 42 age group, caries was by far the most prevalent reason for tooth extractions, but over the age of 42 , periodontal disease became the main cause of tooth extraction (Table 2) The highest periodontal extraction value $(56.11 \%)$ was seen in age group 55 and above, where individuals experienced significantly fewer caries extractions (3.65\%) than periodontal ones. A total of 1991 teeth were extracted in 1332 individuals. Molar and premolar presented $96.57 \%$ of the carious teeth extracted. More carious teeth were extracted from lower jaw (52\%) than the upper one $(48 \%)$. There were more anterior teeth extracted for periodontal reasons from lower jaw (97.60\%) (Table 3). Among the teeth extracted for reasons other than caries and periodontal disease, upper anterior teeth were the most numerous (13.90\%). These upper anterior teeth were extracted as they were either over retained primary teeth or affected from trauma. Very few third molar extractions were done. Percentage of periodontal disease and caries teeth extraction was high in male individuals (Table 4). 
Table 1: Age and Sex-wise distribution of study population (\%).

\begin{tabular}{|c|c|c|c|}
\hline Age (Years) & Male & Female & Total \\
\hline 11-Jun & $51(6.19)$ & $31(6.09)$ & $82(6.15)$ \\
\hline $18-\mathrm{Dec}$ & $40(4.86)$ & $21(4.12)$ & $61(4.57)$ \\
\hline $19-24$ & $70(8.50)$ & $50(9.82)$ & $120(9.09)$ \\
\hline $25-30$ & $68(8.26)$ & $49(9.62)$ & $117(8.78)$ \\
\hline $31-36$ & $66(8.01)$ & $81(15.91)$ & $147(11.03)$ \\
\hline $37-42$ & $57(8.92)$ & $54(10.60)$ & $111(8.33)$ \\
\hline $43-48$ & $79(9.59)$ & $45(8.84)$ & $124(9.30)$ \\
\hline $49-54$ & $87(10.57)$ & $68(13.35)$ & $155(11.63)$ \\
\hline $55+$ & $305(37.05)$ & $110(21.61)$ & $415(31.15)$ \\
\hline Total & $823(61.78)$ & $509(38.21)$ & 1332 \\
\hline
\end{tabular}

Table 2: Age-wise distribution and cause for extracted teeth. (\%).

\begin{tabular}{|c|c|c|c|c|}
\hline Age (Years) & Periodontal & Dental caries & Others & Total \\
\hline $06-11$ & $2(0.28)$ & $77(13.39)$ & $3(4.83)$ & 82 \\
\hline $12-18$ & $1(0.14)$ & $52(9.04)$ & $8(12.90)$ & 61 \\
\hline $19-24$ & $7(1.07)$ & $96(16.69)$ & $17(27.41)$ & 120 \\
\hline $25-30$ & $6(0.86)$ & $97(16.86)$ & $14(22.58)$ & 117 \\
\hline $31-36$ & $35(5.03)$ & $103(17.91)$ & $9(14.51)$ & 147 \\
\hline $37-42$ & $37(5.32)$ & $68(11.82)$ & $6(9.67)$ & 111 \\
\hline $43-48$ & $80(11.51)$ & $43(7.47)$ & $1(1.61)$ & 124 \\
\hline $49-54$ & $137(19.71)$ & $18(3.13)$ & Nil. & 155 \\
\hline $55+$ & $390(56.11)$ & $21(3.65)$ & $4(6.45)$ & 415 \\
\hline Total & $695(52.17)$ & $575(43.16)$ & $62(4.66)$ & 1332 \\
\hline
\end{tabular}

Table 3: Cause of extraction by type of total extracted in upper and lower jaw $(\%)$.

\begin{tabular}{|c|c|c|c|c|c|}
\hline $\begin{array}{c}\text { Cause of Ex- } \\
\text { traction Lower }\end{array}$ & \multicolumn{2}{|c|}{ Anterior } & \multicolumn{3}{c|}{ Premolar } \\
\hline & Upper & Lower & Upper & Lower & Upper \\
\hline Periodontal & 170 & 245 & 131 & 155 & 226 \\
\hline 219 & 527 & 619 & & & \\
\hline Diseases & -76.23 & -97.6 & -69.31 & -84.23 & -47.28 \\
\hline-39.38 & -59.21 & -62.46 & & & \\
\hline Dental Caries & 22 & 1 & 57 & 29 & 245 \\
\hline 321 & 324 & 351 & & & \\
\hline & -9.86 & -0.39 & -30.15 & -15.76 & -51.73 \\
\hline-57.73 & -36.4 & -35.41 & & & \\
\hline Others & 31 & 5 & 1 & Nil & 17 \\
\hline 16 & 39 & 21 & & & \\
\hline & -13.9 & -1.99 & -0.52 & & -1.46 \\
\hline-2.87 & -4.38 & -2.11 & & & \\
\hline Total & 223 & 251 & 189 & 184 & 478 \\
\hline 556 & 890 & 991 & & & \\
\hline
\end{tabular}

Table 4: Sex-wise distribution and total No. Of tooth extracted by its Cause(\%).

\begin{tabular}{|c|c|c|c|}
\hline \multirow{2}{*}{ Sex } & \multicolumn{2}{|c|}{ Cause of Extraction } & \multirow{2}{*}{ Total } \\
\cline { 2 - 3 } & Periodontal Disease & Caries & \\
\hline \multirow{2}{*}{ Male } & $733 / 456$ & $326 / 288$ & $1059 / 744$ \\
\cline { 2 - 4 } & -64.13 & -56.7 & -61.64 \\
\hline \multirow{2}{*}{ Female } & $410 / 239$ & $249 / 212$ & $659 / 451$ \\
\cline { 2 - 4 } & -35.87 & -43.3 & -38.36 \\
\hline \multirow{2}{*}{ Total } & $1143 / 695$ & $575 / 500$ & $1718 / 1195$ \\
\cline { 2 - 3 } & -66.53 & -33.47 & \\
\hline
\end{tabular}

\section{Discussion}

The method utilized in present study is unique in that it is a prospective study, involving single central source of diagnosis. Previous studies $[9,10]$ used the examination of extracted teeth. Cahen et al [11] followed the postal survey of dentists. The periodontal disease was responsible for maximum extraction of teeth $(60.93 \%)$ in $52.17 \%$ of the individuals, which is similar to previous studies conducted in India [1-4]. Studies conducted outside India have also reported periodontal disease as the main etiological factor for extractions after 40 years of age [12-14]. Number of extracted teeth due to periodontal disease in male individual was $64.13 \%$ while in female it was only $35.87 \%$. This was thought to be due to high prevalence of betel nut, pan and tobacco habit in male individual. Bhowate [15] et al and Davies [16] have proved that betel nut, pan and tobacco chewing and smoking have been associated with increased periodontal disease. In the present study, caries was the main reason for tooth extraction below 42 years. Similar findings were recorded in Swedish [10] and French [11] study. Molar represented $54.97 \%$ of the total teeth extracted for caries and $43.03 \%$ of the teeth for periodontal extractions, which is similar to Cahen [11] study in France.Molars accounted for $64.20 \%$ of tooth loss due to caries in a study conducted by Dosumu [17].

\section{Following Conclusions can be Drawn from the Present Study}

a) Periodontal disease was a major cause for extraction of teeth in whole sample.

b) Caries was the main reason for extraction in patients under 42 years.

c) Periodontal disease was a main reason for tooth removal in patients over 42 years.

\section{References}

1. Subramanian V (1951) Cause for the extraction of teeth amongst hospital patients. J Indian Dent Assoc 23: 5-6.

2. Lal D, Sing Jand Khanna SL (1958) Cause for the extraction of teeth. J Indian Dent Assoc 30: 75-77.

3. Mehta FS, Sanjana MK, Shroff BC, Doctor RM (1960) An analysis of periodontal disease as a cause of tooth loss. J Indian Dent Assoc 32: 71-76. 
4. Mathur MN, Nath S (1968) Tooth Mortality. An analysis of extraction causes. J Indian Dent Assoc 40(8): 213-215.

5. Chawla HS (2002) Prevalence of Dental caries in India. J Indian Soc Pedod Prev Dent 20(4): vi-vii.

6. Mandal KP, Tewari AB, Chawla HS, Gauba KD (2001) Prevalence and severity of dental caries and treatment needs among population in the Eastern states of India. J Indian Soc Pedod Prev Dent 19(3): 85-91.

7. Tewari S (2001) Caries experience in 3-7 year old children in Haryana (India). J Indian Soc Pedod Prev Dent 19(2): 52-56.

8. Sing DK and Sing RP (1981) Prevalence of dental caries in school going children of Patna. J Indian Dent Assoc 53: 267.

9. Bouma J, Schaub RMH, Van de Poel ACM (1985) Periodontal starus and tooth extraction in a medium sized city in the Netherlands. Community Dental Oral Epidemiol 13(6): 323-327.

10.Lundquist C (1967) Tooth mortality in Sweden. A stastical survey of tooth loss in Swedish population. Acta Odontal Scand 25(3): 289-322.
11.Cahen PM, Frank RM , Turlot JC (1985) A survey of the reasons for dental extractions in France. J Dent Res 64(8): 1087-1093.

12.Quetish Taani DS (2003) Periodontal reasons for tooth extractions in an adult population in Jordan. J Oral Rehabil 30 (1): 110-112.

13.0ng G, Yeo JF, Bhole SG (1996) A survey of reasons for extractions of permanent teeth in Singapore. Community Dent Oral Epidemol 24 (2): 124-127.

14.Haddad I, Aaddadin K , Jebrin S , Maan m , Yassin O (1999) Reasons for extraction of permanent teeth in Jordan. Int Dent J 49(6): 343-346.

15.Bhowate RR, Jawle SS, Rao SP (1991) Epidemiology of oral premalignant lesions in rural areas of Wardha district. Oral Oncology 2: 24-27.

16.Davies GN (1940) Social customs and habits and their effects on oral diseases. J Dent Res 42: 209.

17.Dosumu 00, Denloye 00 (1999) Pattern of permanent tooth loss in Nigerian children and their prosthetic replacement. Afr J Med Sci 28(1-2): 31-3.

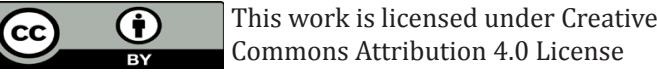

To Submit Your Article Click Here:

Submit Article

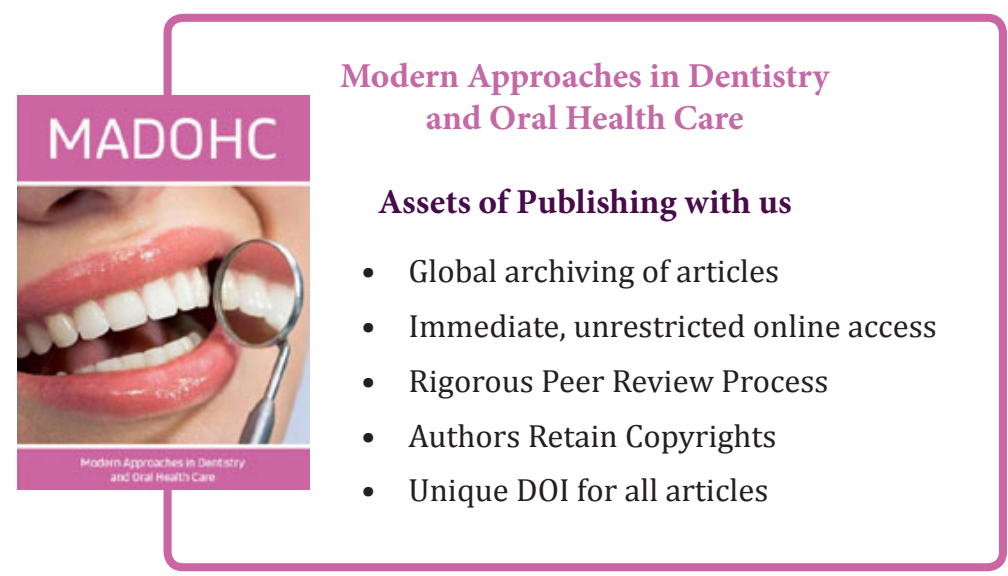

